\title{
Vaccine diplomacy: nation branding and China's COVID-19 soft power play
}

\author{
Seow Ting Lee ${ }^{1}$
}

Revised: 18 June 2021 / Accepted: 30 June 2021 / Published online: 6 July 2021

(c) The Author(s), under exclusive licence to Springer Nature Limited 2021

\begin{abstract}
As a global crisis, COVID-19 has altered how nation-states project influence. Public health has risen to the top of every agenda as individuals, societies, and nation-states focus on a common goal. With the advent of COVID-19 vaccines, homegrown national vaccines when distributed all over the world can play an integral role in nation branding as a technique for projecting soft power. This paper applies the theoretical lenses of nation branding and soft power to examine China's bilateral vaccine diplomacy efforts, specifically the motivations and outcomes. The findings suggest that Chinese vaccines are used not only for image repair and for expanding Beijing's great power ambitions, but also to reinforce and leverage existing soft power programs, and to capitalize on new economic and geopolitical opportunities. Vaccine diplomacy is a natural extension of Chinese soft power including prior engagement in health diplomacy. Sentiment analyses of social media and international media coverage suggest that where vaccines go, influence may follow. Although international sentiments are not all positive-with concerns over Chinese vaccines' efficacy, safety, and data availability, Beijing reaped substantial soft power dividends through its ability to project influence in scientific prowess and civic virtue by providing the vaccines as International Public Goods through aid and gifts to countries left behind by the vaccine inequity.
\end{abstract}

Keywords Vaccine diplomacy $\cdot$ Soft power $\cdot$ China $\cdot$ Public diplomacy $\cdot$ Nation branding $\cdot$ COVID-19 $\cdot$ Pandemic $\cdot$ Health $\cdot$ Vaccines

\section{Introduction}

COVID-19 vaccines have emerged as a new public diplomacy instrument as China, India, Russia, and increasingly the U.S. compete to project influence through donations or loans of their home-grown vaccines and the inking of vaccine purchase agreements with countries who have less access to vaccines. China, in particular, has a significant lead in the vaccine diplomacy race so far. As of March 2021, Beijing has provided millions of free doses to 69 countries and commercially exported many more to 28 other countries (Huang 2021). China's vaccine diplomacy began in July 2020 when the first Chinese vaccine trial outside China commenced in Brazil. As early as November 2020, China vaccine companies signed deals with dozens

Seow Ting Lee

seowting.lee@colorado.edu

1 Department of Advertising, Public Relations, and Media Design, University of Colorado at Boulder, 1511 University Avenue, UCB 478, Boulder, CO 80309, USA of countries - mostly lower and middle income-to supply them with Chinese-made vaccines. On Dec 21, 2020, Egypt became one of the first countries to accept vaccines from Chinese state-owned vaccine maker Sinopharm. The destinations of Chinese vaccines are consistent with Beijing's public diplomacy efforts including development aid and business activities since the mid-1990s that have focused on Asia, Africa, and Latin America-areas sometimes neglected or deliberately isolated, because of their repressive regimes, by the U.S. and Europe.

This paper applies intersecting conceptual lenses of public diplomacy and nation branding to explicate China's vaccine diplomacy and to examine the outcomes in soft power dividends. Since the virus was first reported in Wuhan, China in late 2019, China has experienced a reputational rollercoaster, garnering international sympathy, as well as accusations of fanning the pandemic by silencing early reports. Since then, Beijing continues to be dogged by international criticisms that trace the origins of the pandemic to a leak from a Wuhan lab. 
After a successful domestic COVID-19 mitigation, China launched a public diplomacy campaign in April 2020 to brand itself as a global health leader (Lancaster and Rubin 2020) by sending masks, medical teams, and test kits overseas. Beijing's resurrection of the Health Silk Road moniker to promote its health leadership and redeem its international image is a natural extension of its mask diplomacy. As China attempted to turn its health crisis into a geopolitical opportunity, its vaccine diplomacy raised more than a few eyebrows as China's competitors worry that "where Beijing's inoculations go, its influence will follow" (Huang 2021).

This study is the first to empirically investigate vaccine diplomacy in the COVID-19 context. An examination of China's vaccine diplomacy will clarify the conceptual relationships between and among soft power, public diplomacy, and nation branding. Although much has been written in the popular press and trade journals about COVID-19 vaccine diplomacy (Ellwood 2021; Huang 2021; Lawler 2021; Watson 2021; Wheaton 2020), no published study has hitherto analyzed the motivations and outcomes of COVID-19 vaccine diplomacy.

As instruments of soft power and nation branding, vaccines can help foster a favorable country image and likeability, as "few areas of diplomatic goodwill connect more with the humanitarian nature of international citizenship than medical assistance" (Bier and Arceneaux 2020, para. 9). Vaccine diplomacy is an appealing instrument for projecting soft power, or power of co-optation, what Nye (2008) described as "the ability to affect others to obtain the outcomes one wants through attraction rather than coercion or payment" (p. 94).

\section{From medical diplomacy to vaccine diplomacy}

Vaccine diplomacy can be better understood within the broader conceptual category of medical diplomacy, a term that was coined in 1978 by Peter Bourne, special assistant to the president for health issues in the Carter administration. Bourne (1978) argued that health and medicine can play an important role "as a means for bettering international relations" as "certain humanitarian issues, especially health, can be the basis for establishing a dialogue and bridging diplomatic barriers because they transcend traditional and more volatile and emotional concerns" (p. 121). During the Cold War, the U.S. and Russia worked together to fight polio. Cuba was one of the first states to deploy medical diplomacy as a foreign policy instrument. The socialist state, isolated and eager to exert soft power, sent medical aid and its doctors and nurses to natural disasters including the 1960 Chile earthquake, and more recently to the 2014 Ebola outbreak in West Africa (Bier and Arceneaux 2020; Gomez 2014; Groll 2013).

In recent years, medical diplomacy has grown into an established area of study more commonly known as global health diplomacy, driven by a growing realization that an increasing range of health issues and their broad political, social, and economic implications now transcend national boundaries and require action on the global forces that determine the health of citizens (Kickbusch et al. 2007). As noted by Cooper (2003), "[i]n the past, it was enough for a nation to look after itself. Today it is no longer sufficient" (p. 12).

However, the term global health diplomacy continues to convey different conceptual meanings despite being anchored in the core constructs of interdependence, cooperation, and mutual benefit. According to Katz et al. (2011), the conceptualizations of global health diplomacy generally fall into three different categories of interaction around international public health issues: (1) core diplomacy: formal negotiations between and among nations; (2) multistakeholder diplomacy: negotiations between or among nations and other actors, not necessarily intended to lead to binding agreements; and (3) informal diplomacy: interactions between international public health actors and their counterparts in the field, including host country officials, nongovernmental organizations, private-sector companies, and the public.

Hotez (2014) defined vaccine diplomacy as "almost any aspect of global health diplomacy that relies on the use or delivery of vaccines and encompasses the important work of the Gavi, the Vaccine Alliance, as well as elements of the WHO, the Gates Foundation, and other important international organizations" (p. 43). Gavi, the Vaccine Alliance was founded in 2000 to bring together public and private sectors and their UNICEF and WHO partners with the shared goal of creating equal access to vaccines in poor countries. Hotez (2014) observed that vaccine diplomacy is as old as vaccines themselves, describing how British doctor Edward Jenner's smallpox vaccine was shipped to France for successful smallpox inoculations at a time of almost continuous warfare between Britain and France during the early 1800s. Like Hotez (2001, 2010, 2014), Shakeel et al. (2019) defined vaccine diplomacy as a branch of global health diplomacy "that promotes the use and delivery of vaccines to achieve larger global health goals and shared foreign policy objectives" (p. 82). Their explication of vaccine diplomacy focused on the multilateral 2016-2017 WHO-led polio eradication program in Pakistan that involved multiple actors including the Pakistani Ministry of Health, Regulations and Coordination and donors and technical partners including the U.S. CDC, World Bank, U.K. Department for International Development (DFID), and Japan International Cooperation agency (JICA).

Hotez (2014) further identified vaccine science diplomacy as a subset of vaccine diplomacy. Vaccine science diplomacy, 
representing hybrid characteristics of global health diplomacy and science diplomacy, refers to "the joint development of life-saving vaccines and related technologies, with the major actors typically scientists." In some instances, the scientists may come from two or more nations that are ideologically opposed or nations actively engaged in hostile actions, as seen in the Jenner smallpox vaccine case. Hotez's definition of vaccine science diplomacy fits into Katz et al.'s (2011) framework of global health diplomacy, specifically their category of informal global health diplomacy based on peer-to-peer scientific interactions together with elements of science diplomacy in which "the representative nation projects power through its scientific prowess and reputation" (Hotez 2014, p. 123), especially when other forms of dialog are blocked (Ruffini 2017). However, Katz et al.'s (2011) conceptualization of global health diplomacy does not take into consideration the uniqueness of vaccines, especially in the context of a globally debilitating pandemic. Hotez (2014) rightly argued that an underlying theme of both vaccine diplomacy and vaccine science diplomacy is that vaccines are different from other medical or public health interventions. By some estimates, modern vaccines-the single most powerful scientific intervention ever developed-have saved more lives than those that were lost in the world (Hotez 2014).

In sum, pre-COVID-19 definitions and conceptualizations of vaccine diplomacy (Hotez 2014; Kelman 2019; Shakeel et al. 2019) as an agent of conflict resolution, when viewed together with Katz et al.'s (2011) framework for explicating global health diplomacy, ignores the agency of the individual nation-state and the element of competition on display in the current COVID-19 vaccine diplomacy race. Ontologically, China's vaccine diplomacy does not adhere to pre-COVID conceptualizations of vaccine diplomacy within a limited framework of multilateral conflict resolution. The conceptual tensions between mutual benefit and self-interest become clear when we apply the lens of nation branding, what Anholt (2007) has proposed as a metaphor for describing how effectively individual nation-states compete with each other for favorable perception, be it through exports, governance, tourism, investment, culture and heritage, and people—or in China's case, COVID-19 vaccines.

The Chinese conceptualization of COVID-19 vaccine diplomacy as a bilateral construct outside of COVAX (an international partnership led by the Coalition for Epidemic Preparedness Innovations, Gavi, the Vaccine Alliance, and the WHO) can be better understood within the context of China's approach toward public diplomacy in general.

\section{China's model of public diplomacy}

The origins of modern-day Chinese public diplomacy can be traced to the 1950s. The Chinese classify public diplomacy based on political leadership. Under Mao Zedong, the country applied Civic Diplomacy in response to international isolation, focusing on official, semi-official, and civilian exchanges (Li and Wong 2018). Under Deng Xiaoping's open-door policy, Civic Diplomacy had to expand beyond the limited goal of creating a favorable image of a closed and autarkic country (D'Hooghe 2011) to focus on understanding with other countries to create a stable environment for China's economic reforms. Since the 2020s, under Hu Jintao and his successor Xi Jinping, China has paid more attention to public diplomacy as it seeks to rebrand its role on the world stage. Under $\mathrm{Xi}$, the goal of public diplomacy is to communicate the China Dream to the international community by highlighting Chinese characteristics and striving for worldwide understanding and support. The focus is on "explaining China to the world" (Xi 2014, p. 1). At the same time, the China Dream is associated with the wish for a better life for all peoples in China's neighboring countries and potential regional development prospects through the idea of "a community of shared future for mankind" (Xi Jinping makes 2013, para. 3).

China has a unique model of public diplomacy (Zhao 2019; Yang 2020). There is no literal equivalent of "public" in the Chinese language, which uses the term "public" to refer to "governmental affairs" instead (Zhao 2019, p. 170). Although China's public diplomacy has been influenced by American and European theories and models from the very beginning, the "China Model" of public diplomacy has evolved through distinct Chinese characteristics including emphases on ideological leadership, cultural self-confidence, cultural and people-to-people exchanges, and the provision of public goods for the international community.

China's model of public diplomacy is characterized by a centralization of power in the Chinese Communist Party (CCP) Central Committee, and a management approach featuring cultural-rather than institutional-coordination (Zhao 2019). The power structure is based on a system of "party-led" diplomacy with the CCP's Central Foreign Affairs Leading (Small) Group coordinating all diplomatic matters. This is different from the case in most countries, where foreign ministries are the most important state actors in public diplomacy. Under cultural institutionalization, although state actors such the Ministry of Foreign Affairs, the Ministry of Culture, and the Ministry of Commerce, and non-state actors such as academics, NGOs, overseas Chinese communities, and "friendship" associations are involved in public diplomacy, "none have sufficient legal basis to act as the specialized agency of public diplomacy" (p. 173). 
In China's vaccine diplomacy, state-led engagement has dominated the production, marketing and distribution of COVID-19 vaccines. In Serbia, one of the many recipients of China's Sinopharm doses, China sent its ambassador to Serbia to the airport in a glitzy ceremony celebrating the arrival of the vaccine. In contrast, the U.S., the U.K., and other European states "preferred to let pharmaceutical companies take the spotlight, and largely allowed them to decide where vaccines go and in what quantities" (Safi 2021, para. 10). Under such a commercial for-profit model, doses are distributed to the highest bidders.

Under Xi's China Dream, Beijing is turning increasingly to soft power as the government promised to deliver a rejuvenated China that wields more influence across the world (Biswas and Hartley 2017). Xi made this historic pronouncement of a rejuvenated China at China's 19th Party Congress meeting of 2017, capitalizing on the inward turn of the U.S. under Trump who seemed more preoccupied with turbulent politics at home. As an economic soft power initiative, China's Belt and Road project, launched in 2013, has gathered significant momentum, with more than 60 countries, accounting for two-thirds of the world's population, having signed up for expressed interest in exports of Chinese-style economic growth via massive investments in infrastructure.

China's soft power play has also emphasized cultural projection, which was accelerated by Hu Jintao. By some accounts, China was spending more than $\$ 10$ billion a year in a soft power push to focus on academic exchanges and promotion of language and culture (Krasnyak 2018). The most significant—and controversial—cultural exports are Confucius Institutes, Beijing-affiliated teaching and research centers housed in colleges and universities worldwide and supported by the network of cultural agencies and embassies overseas.

Consistent with the "Chinese Threat" theory that has gained traction in the international community since the 2000s, popular discourse and media reports have dismissed China's vaccine diplomacy as a public relations exercise. It is compelling to more comprehensively understand Beijing's motivations. Thus, this paper seeks to address this research question: (RQ1) What are the motivations behind China's COVID-19 vaccine diplomacy?

\section{Nation branding through vaccines}

Broadly, nation branding refers to the purposeful cultivation of a country's whole image on the international stage, covering political, economic, and cultural dimensions with goals to reform, repair, enhance, or remake an existing country's image to make it more attractive and competitive (Anholt 2007; Fan 2006; Quelch and Jocz 2004). Fan (2010) observed that "nation branding can be used as an important tool in developing and maintaining a country's soft power" (p. 100) as "branding is the process of designing, planning and communicating the name and the identity, in order to build and manage the reputation" (Anholt 2007, p. 4). The images of a nation "can be created or altered, monitored, evaluated and proactively managed in order to enhance the country's reputation among a target international audience" (Fan 2010, p. 101).

A nation brand is a complex, multifaceted, and relative concept that thrives on differentiation and competition. Every nation has a "brand," with or without any efforts in nation branding, because "each country has a certain image to its international audience, be it strong or weak, current or outdated, clear or vague" (Fan 2006, p. 12). As a "mental image of the country held by foreign people," a nation brand is "the total sum of all perceptions of a nation in the minds of international stakeholders" (Fan 2010, p. 98), which may contain some of the following elements: people, place, culture/language, history, food, and so on. It is "a complex bundle of images, meanings, associations and experiences in the minds of people" (p. 98) and "the unique, multi-dimensional blend of elements that provide the nation with culturally grounded differentiation and relevance for all of its target audiences" (Dinnie 2008, p. 15). There is a positive relationship between nation branding and soft power: "[i]f nation branding as a technique for soft power is used strategically, it projects a positive image of the country and consequently the country will gain soft power" (Kahraman 2017, p. 94).

Anholt (2007) viewed the competition for favorable perception as a powerful political tool, especially among peripheral nations or middle powers eager to strengthen their positions and to compete against the clout of superpowers. Competitive Identity (Anholt 2008) "has more to do with national identity and the politics and economics of competitiveness than with branding as it is usually understood in the commercial sector" (p. 22). Identity is "competitive" due to the effects of globalization, where rankings and indices pit nations against one another in every sector, whether it is tourism, standard of living or health-and more recently, COVID-19 efforts.

In COVID-19, countries have unique nation brands associated with the pandemic; in the minds of international audiences, one country may be a success story while another is a failure with poor governance, high fatalities, and inadequate vaccine doses. How these "mental images of the country held by foreign people" (Fan 2010, p. 68) when challenged or augmented by vaccine diplomacy, could translate into country reputation is a question worth addressing.

To this end, this paper addresses a second research question: (RQ2) What are the soft power outcomes of China's vaccine diplomacy? It is compelling to investigate the extent to which China's vaccine diplomacy was effective in helping the country "communicate with and attract the publics 
of other countries" (Nye 2008, p. 4) for nation branding. Prior to the pandemic, China's nation brand has consistently deteriorated, and the huge investments in public diplomacy have not resulted in a proportionate increase in its international image (Cao 2016, D’Hooghe 2011; Nye 2015; Yang 2020) to help it overcome the structural weakness it faces in the global opinion market. Nye (2015) observed that as long as Beijing fans the flames of nationalism and holds tight the reigns of party control, China's soft power will remain limited.

In the latest Global Soft Power Index released on February 25, 2021, China fell three places from fifth place in 2020 to eighth in 2021. China's poorer performance "was likely impacted by the global media coverage of COVID-19 cases in the city of Wuhan, even though the authorities addressed the crisis very effectively and China is one of only a few countries around the world to have got the epidemic under control and to register positive GDP growth at the end of 2020" (Global Soft Power Index 2021). To rank perceptions about 60 nations, the Index surveyed 55,000 members of the global public and over 1,000 specialist experts from 100 countries. Seven pillars of soft power were evaluated: business and trade, governance, international relations, culture and heritage, media and communication, education and science, and people and values. Although China saw a drop in the Governance pillar, as perceptions of China's political system worsened, China—like Russia—saw improved scores of 1.1 and 0.8, respectively, in the Education and Science pillar as "both nations made the significant scientific strides of developing their own vaccines" (Global Soft Power Index 2021).

\section{Method}

A case study approach (Yin 1984, 2002, 2014) was used to analyze the motivations, processes and outcomes of China's vaccine diplomacy. Case studies offer an important method for learning about a complex phenomenon through extensive description and analysis of that instance in its contextual and natural settings (Harling 2012; Yin 1984). Yin (2014) describes case study research as "an empirical inquiry that investigates a contemporary phenomenon (the 'case') in depth and within its real-world context" (p. 16).

Primarily exploratory and explanatory, case studies seek to understand an issue in real-life settings through triangulation of sources and methods. Multiple data sources or methods, which are brought together at some stage in a case study, are converging lines of inquiry (Yin 2014). Consistent with an emphasis on triangulation, this study focused on multiple sources of evidence and methods: (1) Secondary data based on country rankings and indices, public data, news media coverage, and government documents. Textual analyses were performed to describe the content, structure, functions of the texts, and their underlying meanings; and (2) Primary data from sentiment analyses of social media postings and international news reports. Sentiment refers to subjective feelings, rather than facts, and includes people's attitude, emotions and opinions (Mullen 2017). Two methods were used to analyze sentiment: a Social Studio analysis and a Leximancer analysis.

In this study, a case study approach premised on triangulation is particularly valuable here. As the topic of vaccine diplomacy in the context of COVID-19 is new, there is a dearth of academic sources and official data. What is "official" with regard to COVID-19 is still subject to controversy, contradictions, and debate.

\section{Findings}

\section{RQ1: motivations behind China's vaccine diplomacy}

Vaccine diplomacy is an attractive public diplomacy tool but not every nation-state is equally interested or able to deploy vaccine diplomacy for projecting influence. Anholt's (2007) explication of nation branding as a strategic, policy-making approach "designed to help places build on the strengths that will earn them a better reputation" (p. 4) emphasized a nation-state's ability or existing strengths. Based on the strength of supply capacity, nine countries (China, the U.S., Russia, the U.K., the EU, Switzerland, India, South Korea) are actively manufacturing COVID-19 vaccines as of March 17, 2021 (Lawler 2021) (see Fig. 1). China is the largest producer with 169.4 million doses of four vaccines: Sinovac, Sinopharm, CanSino, and AstraZeneca (produced in China under a deal with Shenzen Kangtai). As of March 17, 2021, China has manufactured about $33 \%$ of COVID-19 vaccine doses in the world. It is exporting about $62 \%$ of its doses to other countries, which it can do, in part, because it largely has the virus under control domestically-another clear strength. However, supply alone cannot explain why a country deploys vaccine diplomacy. For instance, the U.S. is the second largest producer of four COVID-19 vaccines including AstraZeneca vaccines that are not authorized for use within its borders. The U.S. accounts for $27 \%$ of the world's coronavirus vaccine production, but $0 \%$ of the global supply beyond its own borders (Lawler 2021) - a situation that may change soon with the Biden administration's loans and donations of COVID-19 vaccines to other countries. For the Chinese, vaccine diplomacy is motivated by a combination of exigencies and opportunities. 
COVID-19 Vaccine Production by Country

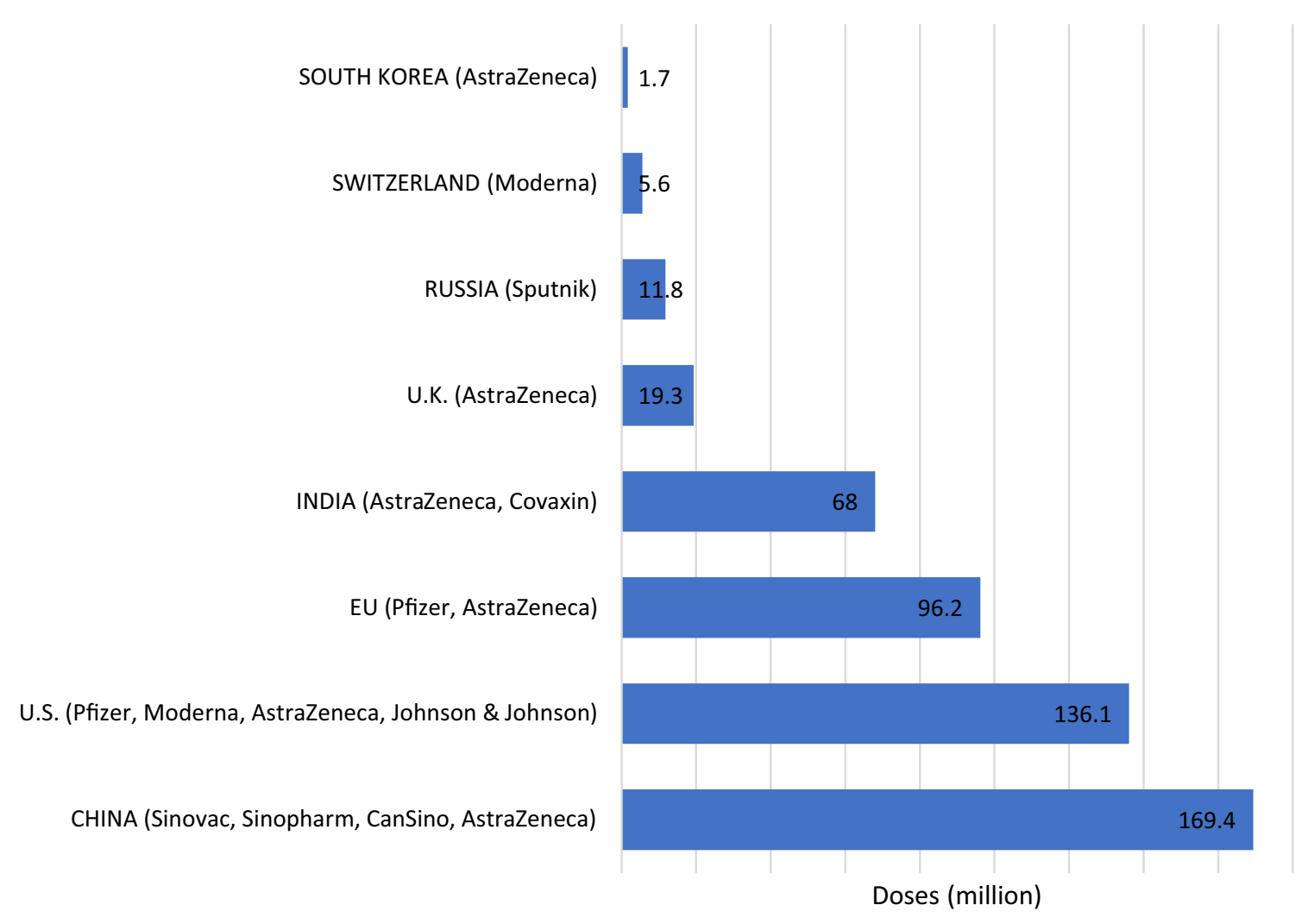

Fig. 1 COVID-19 vaccine production by country. Source Lawler (2021)

\section{Repairing a nation brand}

The Chinese government has been increasingly attentive to China's image in the world. China's COVID-19 vaccine diplomacy was motivated in part by its determination to transform itself from an object of mistrust over its initial mishandling of the COVID-19 outbreak to a savior (Wu and Gelineau 2021a), as part of a broader strategy of reputational damage repair or an image makeover-both at home and in the world. This approach entails reframing its image as the country that accelerated the virus' spread through cover-ups to that of the magnanimous global power offering leadership at a time of international leadership disarray.

Competitive Identity (Anholt 2008) is particularly relevant to nations with poor reputations, as they struggle to compete against nations with good reputations (Anholt 2007). The first step for a nation in developing Competitive Identity is to learn how others view them to begin creating a strategy to reinforce the existing image if it is a positive one, to develop a new image to replace a negative image, or to bolster an image if it was hampered by limited knowledge (Kahraman 2017). In 2020, perceptions of China were negative. Between June 10 and Aug 3, 2020, a Pew Center survey of 14,276 adults in the 14 advanced countries (Belgium,
Japan, Italy, Denmark, France, Australia, Germany, the U.K., the U.S., the Netherlands, Canada, Spain, Sweden, and South Korea) showed that China and the U.S. gathered unfavorable views at or near historic highs in the Center's 12 years of polling on the issue (Silver et al. 2020).

China's poor handling of COVID-10 appeared to be central to its record unpopularity (Silver et al. 2020). A median of $61 \%$ of respondents across all 14 countries polled said China had done a bad job dealing with COVID-19, worse in every case than their own country and global bodies such as the WHO. Only the U.S. receives a worse evaluation, with a median of $84 \%$ saying the U.S. has handled COVID19 poorly (Silver et al. 2020). China's COVID-19 failure was also reflected in the way people in these countries perceived Chinese President Xi. A median of $78 \%$ had no confidence in Xi's ability "to do the right thing in world affairs" although Xi's unpopularity was overtaken by Trump in some countries.

A median of $73 \%$ had negative views of China. Notably, in nine countries (Australia, Germany, the U.K., the U.S., the Netherlands, Canada, Spain, Sweden, and South Korea), China's unpopularity was the highest ever recorded in 12 years. The trend was the strongest in Australia, with 81\%, going up by 24 points over 2019 after a sharp deterioration 
in ties between the two countries. Negative views of China rose by double digits in 2020 over 2019 in the U.K., Germany, the Netherlands, Sweden, the U.S., South Korea, and Spain. More troubling for China is that while these dips since 2019 are stark, in some countries, they reflect a larger trajectory. In the U.S. for example, unfavorable opinion of China trended up steadily since 2018. Similarly, in South Korea, the U.K., the Netherlands, Canada, and Sweden, 2020 marked the second year in a row when negative views of China reached historic highs (Silver et al. 2020).

In the latest Anholt-GfK Nation Brands Index 2020, China's nation brand was battered (Germany Retains Top "Nation Brand 2021") as well. China, whose reputation remained stable at 23rd place over the past four years, saw an overall rank decline of 12 positions from 23rd place last year to 35 th place. China's ranking declined across multiple categories this year-particularly in Governance, People, Tourism, and Immigration Investment.

\section{Soft power vacuum and vaccine nationalism}

China sees the soft power vacuum around vaccines as a geopolitical opportunity. In particular, when viewed in light of contentious U.S.-Sino relations, China's soft power campaign through vaccines is aimed at filling the vacuum left by the Trump-led U.S. retreat from the world diplomatic stage. In a global pandemic, a critical challenge is ensuring widespread global access to vaccines, including in low- and middle-income countries, to achieve needed levels of global population immunity. But months before the first COVID-19 vaccine was even approved, wealthy nations have secured by pre-orders billions of advance doses. By the end of 2020, Canada ordered 338 million doses, enough to vaccinate its population four times over. The U.K. secured three times what it needed to inoculate its citizens. As of February 2021, $56 \%$ of COVID-19 vaccines have been purchased by highincome countries, who represent $16 \%$ of the global population (Lawler 2021), locking in much of the market-highlighting the disparities laid bare by COVID-19 that continue to threaten our collective ability to control the pandemic. This vaccine inequity leaves low- and middle-income countries with limited choices.

Despite international efforts to address vaccine access, most notably through the creation of COVAX, low- and middle-income countries have struggled to procure vaccines for their populations. The UN, describing the vaccine inequity as a "catastrophic moral failure," found that residents in 10 countries have received $80 \%$ of the world's COVID19 vaccine, as of February 2021-prompting it to launch a new global campaign, Only Together, to advance fair and equitable access to COVID-19 vaccines worldwide (UN launches Only Together 2021). Leveraging on the vaccine inequity, China has targeted the low- and middle-income countries largely left behind as rich nations scooped up most of the pricey vaccines produced by Pfizer and Moderna, and capitalized on slower-than-hoped-for deliveries by U.S. and European vaccine makers. In Chile, when its vaccination program began in late December 2020, only 150,000 of the 10 million Pfizer doses ordered arrived. China swooped in offering four million Sinovac doses in late January ( $\mathrm{Wu}$ and Gelineau 2021b), helping the South American country to reach the fifth highest vaccination rate per capita in the world by March 2020, according to Oxford University's vaccination tracker (COVID-19 data explorer 2021).

China's vaccine diplomacy efforts, along with that of Russia and India, also capitalized on the vaccine nationalism of western countries. As China, Russia, and India engaged in a flurry of deals, free samples, and donations of their vaccines outside their borders, "[c]onspicuously missing so far from the fray of overseas deals and donations have been western governments, which are consumed with vaccinating their own populations first and have preferred to channel vaccine aid into multilateral schemes such as COVAX" (Safi 2021, para. 7). French President Emmanuel Macron conceded that a vaccine rollout to rich countries ahead of poor nations was "an unprecedented acceleration of global inequality" that is also politically unsustainable "because it is paving the way for a war of influence over vaccines-you can see the Chinese strategy and the Russian strategy too" (as cited in Doherty 2021, para. 26).

\section{Vaccines as International Public Goods (IPGs)}

Rhetoric alone cannot sell a nation brand in a pandemic, especially when it relates to a matter of fundamental import such as health. Given that factual basis (Kahraman 2017) or substance (Lee and Kim 2020) is fundamental to nation branding, a nation-state's ability to project soft power in the COVID-19 context may be associated positively with perceived efficacy of its pandemic response but perhaps equally important is the nation-state's ability to contribute life-saving vaccines-as International Public Goods (IPGs) - to countries who need them. Chinese vaccines, based on inactivated virus, do have a factual edge or substance; they do not require cold storage infrastructure for distribution (Hu 2020; McGregor 2020). Thus, they are particularly appealing to many developing countries, daunted by the challenges of importing and transporting the mRNA vaccines of Pfizer and Moderna that require sub-zero facilities. The competitiveness of COVID-19 vaccines provides a space for vaccine diplomacy. Chinese State media emphasized how African and some Latin American states prefer Chinese inactivated vaccines, due to their competitive costs and easier logistics considering tropical heat, distance, and scarcity of ultra-cold freezers (Hu 2020). Tropical Indonesia, the world's fourth-most populous nation, declared it cannot 
use the Pfizer vaccine given the logistical challenges in distributing it (McGregor 2020). In December 2020, Indonesia received 4 million Sinovac doses and began inoculating its citizens with a goal to vaccinate 181.5 million people over 18 or $67 \%$ of its 270 million citizens within 15 months with Chinese vaccines (Bryne 2021).

Few goods are pure IPGs (nonexcludable, nonrivalrous, and generally available worldwide) but COVID-19 vaccines come very close in the minds of Chinese leaders. In May 2020, Xi proclaimed that Chinese-made COVID-19 vaccines would become an IPG. Speaking to the World Health Assembly, Xi noted that the vaccines "will be China's contribution to ensuring vaccine accessibility and affordability in developing countries" (as cited in Wheaton 2020, para. 3 ) and that international vaccine distribution would be part of China's vision of a "shared future for the people of the world to work as one" (as cited in Doherty 2021, para. 1). This attempt to convince the world that China is a virtuous great power and subsequent statements by the Ministry of Foreign Affairs echoed Xi's framing of the vaccines as IPGs.

Framing vaccines as IPGs, Beijing studiously rejected any connection between the export of its vaccines and its image. Speaking in Moscow in March 2020, China's foreign minister Wang Yi said that it was hypocritical of critics to suggest China was "scheming to conduct some kind of vaccine diplomacy," and accused western countries of "selfish mass hoarding of vaccines" (as cited in Doherty 2021, para. 28). "I don't see any linkage there," said Wang Huiyao, president of the Center for China and Globalization, a Beijing think tank. "China should do more to help other countries, because it's doing well" (as cited in Wu and Gelineau 2021b, para. 8). The rhetorical framing of COVID-19 vaccines as IPGs is consistent with Chitty's (2017) explications of soft power as civic virtue, in which "[s]tates and peoples operate in an international environment where virtue associated with nurturing the public good and actively engaging in the public sphere is valued, even if adherence to these values is variegated" (p. 29).

Public goods was first coined by economist Erik Robert Lindahl in his book Just Taxation (1919) in the context of domestic governance, but the term IPGs was first used by Olson and Zeckhauser (1966) in their study of NATO's international role in maintaining common security. In 2005, China embraced the language of public goods for the first time in a White Paper of the Information Office of State Council (Zhao 2017). Public goods were then domestically oriented, focusing on education, science and technology, culture, health care, and other social areas. By 2011, Chinese diplomats began expressing that China should provide IPGs such as peace, development, and other contributions to the world (Zhao 2017). Since then, Chinese leaders have argued for more emphasis on IPGs as a public diplomacy instrument for global leadership. In the China Arabic Cooperation
Forum on June 5, 2014, Xi explicitly used the term IPGs to emphasize China's intent to create and provide such goods to the world.

Within the context of emerging anti-globalization around the world, China's focus on IPGs aims to drive the nation further along the track of global leadership alongside the U.S. (Preston et al. 2016; Zhao 2017). Since the 1980s, Beijing has expressed a strong opposition against all forms of hegemony in foreign affairs although it has also expressed a growing interest in providing IPGs. To some extent, China's motivation to provide COVID-19 vaccines as IPGs could be viewed as hegemonic in substance and intent. According to the theory of hegemony, providing public goods was the inherent responsibility of hegemon states such as Great Britain and the U.S. because it would also benefit their own interests. Zhao (2017) speculated that China could use IPGs as a method to develop into a hegemonic power although he also argued that China remains anti-hegemonic because it is not yet a superpower.

On October 9, 2020, after months of hesitation-and shipping Chinese-made vaccines overseas bilaterally, China finally joined COVAX, which aimed to provide two billion doses of vaccine to the most vulnerable people and to healthcare workers, especially in poor nations. In a statement on the Chinese Foreign Ministry's website, China's Foreign Ministry spokeswoman Hua Chunying said: "We are taking this concrete step to ensure equitable distribution of vaccines, especially to developing countries, and hope more capable countries will also join and support COVAX" (Ministry of Foreign Affairs 2020, para. 2).

Although there is some speculation that Beijing changed its mind about COVAX after polls by the Pew Research Center revealed that negative views toward China deepened during the pandemic, China's decision was warmly welcomed by many. In a tweet, Seth Berkley, the CEO of Gavi, wrote: "I am delighted to welcome China into the \#COVAX facility. This announcement gives even more momentum to our mission to ensure future \#COVID vaccines are distributed equitably because no one is safe until everyone is safe."

\section{Mixing politics and business}

China's vaccine diplomacy adheres to a mixed model of business and politics, as doses are "used as a tool, to reinforce established relations and capitalize on new opportunities" (Karásková and Blablová 2021). Contrary to the altruistic, civic-virtue framing of vaccines by the Chinese government as IPGs and China's contribution to ensuring vaccine accessibility and affordability in developing countries, few doses were free. China distributed free doses to some countries in the form of donations but offered to others doses for purchases or loans to buy the vaccines. The loan arrangement appeared to be aimed primarily at Latin 
American and Caribbean countries (Karásková and Blablová 2021). Table 1 shows the open-source data on the distribution of Chinese vaccines, including information about country destination, vaccine, distribution method (including third-country government donations), and quantity (Blablová 2021).

The public data suggest that less than $2 \%$ of the doses were in fact free (donations); out of the 656 million doses distributed worldwide by China, only 8.6 million doses $(1.31 \%)$ were donations. The donations were dominated by Sinopharm vaccines, relative to the other two Chinese vaccines, CoronaVac (made by Sinovac) and Conviecia (from CanSino Biologics). The pricing of Chinese vaccines, contrary to expectations, is not cheaper than vaccines produced by other countries or vaccine makers. Reported prices for Sinopharm doses ranged from $\$ 18.50$ per dose in Senegal to $\$ 44$ inside China (Beaubien 2021) to up to $\$ 72.50$ per dose when first announced by Sinopharm Chairman Liu Jingzhen (Liu 2020).

In business, giving out a free sample is often an effective tactic to draw interest and secure a future sale. China gave out small amounts of free samples as donations that resulted in much larger purchases of its vaccines. For instance, China donated 600,000 doses of its Sinovac vaccine to the Philippines who went on to purchase 25 million doses. It donated 50,000 Sinopharm doses to Iraq that resulted in a sale of two million doses to the Iraqis (Table 1).

From a business perspective, China's vaccine diplomacy was also guided by a strategy of avoiding direct competition with Pfizer or Moderna in developed countries, where "Chinese-developed vaccines are shunned by Western market due to the West's lack of trust and familiarity with Chinese vaccines and their approval standards" (Hu 2020, para. 14). Its vaccine distribution started closer to home, with nine out of the 10 ASEAN countries (except Vietnam) using or on track to use Chinese vaccines. In south Asia, China won over Pakistan and Nepal but had to contend with India's vaccine diplomacy when Sri Lanka and Bangladesh opted for Indian vaccines despite being offered Chinese vaccines (Table 1).

The case of Paraguay - one of only 15 countries that recognize Taiwan-offers some insight into the politics of vaccines. Paraguay, who does not recognize the government in Beijing, accessed 20,000 Sinovac doses through a donation from neighboring Chile (Karásková and Blablová 2021). In April 2020, as COVID-19 raged through Paraguay, the leftist bloc in the Paraguayan Senate introduced a bill to open relations with Beijing, which would mean cutting ties with Taiwan. The bill's supporters argued that it would pave the way for crucial Chinese support-not only masks and ventilators, but also investment, trade and possibly a vaccine in the near future. The proposal was voted down 25-16 but opposition lawmakers deepened their institutional ties with
Beijing, vowing to recognize China if the balance of power shifts in Paraguay (Nugent and Campbell 2021).

\section{Brand building and leveraging existing relationships}

China's vaccine diplomacy is a continuation of its brand building. Pre-COVID, China had an active health diplomacy program in Africa aimed at "winning the hearts and minds of people in poor countries by exporting medical care, expertise and personnel to help those who need it most" (Fauci 2007, p. 1169). For brand building, Beijing utilized smart power, which combines soft power (culture and health diplomacy) and hard power (the China model and economic power), as China's public diplomacy programming in the continent was linked to aid projects, grants, and low-interest loans for building closer economic ties with African states. During the 2014 Ebola epidemic, China mobilized domestic and international resources and carried out health diplomacy campaigns in Sierra Leone, Liberia, Guinea, and Ghana including sending medical supplies and personnel, and financial donations. In addition, China also engaged local communities through medical training, research exchanges, and cultural events (Chinese State Council Information Office 2014). The existing health diplomacy paved the way for COVID-19 vaccine diplomacy as an expansion of Beijing's decades-long humanitarian assistance to Africa since 1963 (Benabdallah 2021). In sub-Saharan Africa, however, China lagged behind India but this has not stopped Beijing from donating Sinopharm doses to its allies Zimbabwe, Mozambique, and Namibia (Karásková and Blablová 2021). In Zimbabwe, President Emmerson Mnangagwa called China's first batch of donation of 200,000 Sinopharm doses "a light at the end of a dark tunnel," and said that more African countries will benefit from China's assistance (as cited in Ndebele 2021, para. 3).

In South America, Chinese vaccines met with more success, as all countries there opted for Chinese vaccines except Suriname and French Guyana. The Chinese used Brazil as a springboard into the continent, holding Sinovac trials in Brazil that enhanced the credibility of Chinese vaccines despite confusing efficacy data. The Brazilian Sinovac trial involving 13,060 participants that began on July 2, 2020 marked the earliest Chinese vaccine trial outside China (Cohen 2020). Beijing further consolidated its influence within the region as the Brazilians expanded their domestic production of Sinovac.

\section{RQ2: soft power outcome}

A Social Studio analysis of 41,233 English-language posts from Twitter and Instagram users outside China between July 2, 2020 (when the first Chinese vaccine trial outside China commenced in Brazil) and March 27, 2021 based on 
Table 1 Distribution of Chinese vaccines

\begin{tabular}{|c|c|c|c|}
\hline Country & Vaccine & Distribution method & Number of doses \\
\hline Afghanistan & Sinopharm & Donation & 400,000 \\
\hline Algeria & Sinopharm & Donation & 200,000 \\
\hline Argentina & Sinopharm & Purchase & $1,000,000$ \\
\hline Azerbaijan & Sinovac & Purchase & $4,000,000$ \\
\hline Bahrain & Sinopharm & Purchase & 300,000 \\
\hline Bangladesh & Sinovac & Rejected trial deal & \\
\hline Belarus & Sinopharm & Donation & 100,000 \\
\hline Bolivia & Sinopharm & Donation + purchase & $100,000+400,000$ \\
\hline Bosnia and Herzegovina & Sinopharm & Purchase & Not known \\
\hline Brazil & Sinovac & Purchase & $130,000,000$ \\
\hline Brunei & Sinopharm & Donation & Not known \\
\hline Cambodia & Sinopharm & Donation & $1,000,000$ \\
\hline Colombia & Sinovac & Purchase & $5,000,000$ \\
\hline Czech Republic & \multicolumn{3}{|c|}{ Potential use of Chinese vaccines (Sinopharm) } \\
\hline Dominica & Sinopharm & Donation & 20,000 \\
\hline Dominican Republic & Sinovac & Donation + purchase & $50,000+10,000,000$ \\
\hline Ecuador & Sinovac & Donation $(\text { Chile })^{\mathrm{a}}+$ purchase & $20,000+2,000,000$ \\
\hline Egypt & Sinopharm & $\begin{array}{l}\text { Donation }\left(\mathrm{UAE}^{\mathrm{a}} \text { and China }\right)+\text { pur- } \\
\text { chase }\end{array}$ & 100,000 and $300,000+40,000,000$ \\
\hline Equatorial Guinea & Sinopharm & Donation & 100,000 \\
\hline Ethiopia & \multicolumn{3}{|l|}{ Potential use of Chinese vaccines } \\
\hline Gabon & Sinopharm & Donation & 100,000 \\
\hline Guinea & Sinopharm & Donation & 200,000 \\
\hline Guinea-Bissau & Sinopharm & Donation (Senegal) ${ }^{\mathrm{a}}$ & 10,000 \\
\hline Guyana & Sinopharm & Donation & 20,000 \\
\hline Hungary & Sinopharm & Purchase & $5,000,000$ \\
\hline Chile & Sinovac & Purchase & $10,000,000$ \\
\hline Indonesia & Sinovac, Sinopharm, CanSino & Purchase & $125,000,000 ; 15,000,000 ; 15,000,000$ \\
\hline Iran & Sinopharm & Donation & 250,000 \\
\hline Iraq & Sinopharm & Donation + purchase & $50,000+2,000,000$ \\
\hline Jordan & Sinopharm & Purchase & Not known \\
\hline Kenya & \multicolumn{3}{|l|}{ Potential use of Chinese vaccines } \\
\hline Laos & Sinopharm & Donation & 300,000 \\
\hline Lebanon & Sinopharm & Donation & 50,000 \\
\hline Malaysia & Sinovac, Sinopharm, CanSino & Purchase & $12,000,000 ; 2,000,000 ; 35,000,000$ \\
\hline Maldives & Sinopharm & Purchase & 218,000 \\
\hline Mexico & Sinovac, Sinopharm, CanSino & Purchase & $20,000,000 ; 12,000,000 ; 35,000,000$ \\
\hline Mongolia & Sinopharm & Donation & 300,000 \\
\hline Montenegro & Sinopharm & Donation & 30,000 \\
\hline Morocco & Sinopharm & Purchase & $41,000,000$ \\
\hline Mozambique & Sinopharm & Donation & 200,000 \\
\hline Myanmar & Sinopharm, Sinovac & $\begin{array}{l}\text { Donation promised }+ \text { purchase in } \\
\text { negotiation }\end{array}$ & $300,000+$ not known \\
\hline Namibia & Sinopharm & Donation & 100,000 \\
\hline Nepal & Sinopharm & Donation & 500,000 \\
\hline Nigeria & \multicolumn{3}{|l|}{ Potential use of Chinese vaccines } \\
\hline North Macedonia & Sinopharm & Purchase & 200,000 \\
\hline Pakistan & Sinopharm, CanSino & Donation + purchase & $500,000+1,200,000 ; 20,000,000$ \\
\hline Palestine & Sinopharm & Donation & 100,000 \\
\hline Paraguay & Sinovac & Donation $(\text { Chile })^{\mathrm{a}}$ & 20,000 \\
\hline
\end{tabular}


Table 1 (continued)

\begin{tabular}{|c|c|c|c|}
\hline Country & Vaccine & Distribution method & Number of doses \\
\hline Peru & Sinopharm & Purchase & $38,000,000$ \\
\hline Philippines & Sinovac & Donation + purchase & $600,000+25,000,000$ \\
\hline Poland & \multicolumn{3}{|c|}{ Potential use of Chinese vaccines (Sinopharm) } \\
\hline Republic of the Congo & Sinopharm & Donation & 100,000 \\
\hline Senegal & Sinopharm & Purchase & 200,000 \\
\hline Serbia & Sinopharm & Purchase & $2,000,000$ \\
\hline Seychelles & Sinopharm & Donation $(\mathrm{UAE})^{\mathrm{a}}$ & 50,000 \\
\hline Sierra Leone & Sinopharm & Donation & 200,000 \\
\hline Singapore & Sinovac & Purchase & Not known \\
\hline Sri Lanka & Sinopharm & Rejected donation & 300,000 \\
\hline Thailand & Sinovac & Purchase & $2,000,000$ \\
\hline The Gambia & Sinopharm & Donation (Senegal) ${ }^{\mathrm{a}}$ & 10,000 \\
\hline Tunisia & Sinopharm & Donation & 100,000 \\
\hline Turkey & Sinovac & Purchase & $100,000,000$ \\
\hline Uganda & Sinovac & Donation & 300,000 \\
\hline Ukraine & Sinovac & Purchase & $1,800,000$ \\
\hline United Arab Emirates & Sinopharm & Purchase & Not known \\
\hline Uruguay & Sinovac & Purchase & $1,750,000$ \\
\hline Uzbekistan & \multicolumn{3}{|c|}{ Potential use of Chinese vaccines } \\
\hline Venezuela & Sinopharm & Donation & 500,000 \\
\hline Zimbabwe & Sinopharm & Donation + purchase & $400,000+1,800,000$ \\
\hline
\end{tabular}

Source Blablová (2021). Compilation of public data (accessed March 17, 2021)

The data above include countries that have already started inoculation with Chinese vaccines, countries awaiting the first shipment, and countries considering using Chinese vaccines

${ }^{a}$ Third-country donation

the keyword search of "China" and "vaccines" is mostly positive, with $69.7 \%$ positive posts, suggesting a mostly favorable nation brand for China.

To evaluate the international media's perception of China's vaccine diplomacy, this study used Leximancer to analyze English-language media reports published outside the country. Leximancer, a text mining software that scientometrically describes and analyzes content of collections of textual documents, extracts subjectivity in measuring "the attitude of a speaker or writer towards a concept, whether they express something positively or negatively" (Ward et al. 2014). A search under the period of analysis of July 2, 2020 through March 27, 2021 harvested 57,866 English-language texts comprising 48,234 news articles, 5,354 broadcast news transcripts, 2,228 trade publication articles, and 2,050 magazine articles worldwide that focused on China's vaccine diplomacy. A sentiment analysis of the 57,866 texts showed mostly positive sentiments about China's vaccine diplomacy with $71.3 \%$ of texts showing positive mentions.

In Leximancer, a concept is a group of related words that travel together in the text. Evidence words include synonyms and adjectives. Leximancer concepts begin with seed words. The learning process then evolves the seed-word definitions into a full thesaurus that generate concepts that are wordlike or name-like (proper names such as Mary or Pakistan). "Chinese vaccine" was the positive concept with the highest likelihood score at 74\%. Likelihood scores describe the conditional probability of text segments within a concept also containing another concept (Leximancer 2011), meaning that $74 \%$ of text segments with "Chinese vaccine" contained positive sentiments. Other prominent positive concepts include "China" (72\%), "Chinese scientists" (71\%), "donation" (70\%), "aid" (70\%), Sinovac (69\%), "access to vaccines," (69\%), "image" (68\%), "developing countries" (67\%) "ASEAN" (66\%), "economy" (65\%), "Brazil" (61\%), "Africa" (60\%), and "gift" (58\%) (see Table 2). It is worth noting that nation states and regional groupings featured rather prominently in the positive concepts. More significantly, ASEAN, Brazil, and Africa and developing countries were target destinations of Chinese vaccines. Sinovac, among the three Chinese-made vaccines, emerged as a positive concept. Perhaps its salience could be explained by the use of Sinovac in Brazil in the earliest trial of Chinese vaccines on July 2, 2020 that caught the attention of the world. Sinopharm, which dominated donations made by the Chinese government, is not salient. 
Table 2 Sentiment analysis and likelihood scores of each Leximancer concept

\begin{tabular}{|c|c|c|c|}
\hline \multicolumn{2}{|l|}{ Positive concepts } & \multicolumn{2}{|l|}{ Negative concepts } \\
\hline Concept & $\begin{array}{l}\text { Positive } \\
\text { likelihood } \\
(\%)\end{array}$ & Concept & $\begin{array}{l}\text { Negative } \\
\text { likelihood } \\
(\%)\end{array}$ \\
\hline Chinese vaccine & 74 & Vaccine safety & 41 \\
\hline China & 72 & Vaccine efficacy & 40 \\
\hline Chinese scientists & 71 & The U.S. & 38 \\
\hline Donation & 70 & Russia & 36 \\
\hline Aid & 69 & Vaccine data & 35 \\
\hline Sinovac & 69 & Diplomacy & 32 \\
\hline Access to vaccines & 69 & Wuhan & 30 \\
\hline Image & 68 & Trust & 28 \\
\hline Developing countries & 67 & Chinese vaccine & 23 \\
\hline ASEAN & 66 & Vaccine trials & 21 \\
\hline Economy & 65 & & \\
\hline Brazil & 61 & & \\
\hline Africa & 60 & & \\
\hline Gift & 58 & & \\
\hline
\end{tabular}

Ten elements were reported negatively. "Vaccine safety" was the negative concept with the highest likelihood score at $41 \%$, meaning that $41 \%$ of text segments with the term "vaccine safety" contained negative sentiments. This finding is consistent with concerns reported about Chinese vaccines, as seen in the December 2020 YouGov poll that ranked China's vaccine poorly. Another prominent negative concept was "vaccine efficacy" with a likelihood score of $40 \%$, followed by "the U.S." (38\%), "Russia" (36\%), "vaccine data" (35\%), "diplomacy" (32\%), "Wuhan" (30\%), "trust" (28\%), "Chinese vaccine" (23\%), and vaccine trials (21\%) (see Table 2).

In sum, the sentiment analyses of social media and international news media suggest a mostly positive nation brand for China in the context of COVID-19 albeit with related areas of concern about the vaccines' efficacy, safety and data availability, and its relationships with other countries. However, they support the assertions that Beijing's vaccine diplomacy has helped highlight some key areas or specific "mental pictures" that China has sought to associate with the country's global image, such as its scientific prowess, and civic virtue through the framing of donations of vaccines as aid and gifts to developing countries left behind by the vaccine inequity, even when in reality only a small percentage of the doses was actually free. These "mental pictures" are key to building the country's image as a global health leader.

\section{Discussion}

This study fills a gap in the nation branding, soft power, and public diplomacy literature, which has yet to focus on COVID-19 vaccines. Pre-COVID-19 conceptualizations of vaccine diplomacy in the literature, in centering on multilateral frameworks of conflict resolution (Hotez 2001, 2010, 2014; Katz et al. 2011; Kelman 2019; Shakeel et al. 2019), offer limited understanding about bilateral COVID19 vaccine diplomacy. To some extent, China's vaccine diplomacy in subscribing to the notions of civic virtue and IPGs is broadly anchored in the core constructs of interdependence, cooperation, and mutual benefit that characterize global health diplomacy (Cooper 2003; Katz et al. 2011; Kickbusch et al. 2007). However, China's vaccine diplomacy is unique in theory and practice as Beijing seeks a bilateral path using its own interpretations of public diplomacy based on how it views its place in the world and the uniqueness of vaccines that was missing from Katz et al.'s (2011) preCOVID conceptualizations of global health diplomacy. China's model of vaccine diplomacy diverges strikingly from Hotez's (2014) definition of vaccine diplomacy that centers on the role of the Gavi, the Vaccine Alliance, the WHO, and other non-state actors such as the Gates Foundation. It also runs contrary to Hotez's (2014) conceptualization of vaccine diplomacy based on elements of science diplomacy that is premised on peer-to-peer scientific interactions. But if we apply the conceptual lens of nation branding to understand China's vaccine diplomacy, the larger constructs of agency of the individual nation-state, self-reliance, and Competitive Identity (Anholt 2008) are salient in understanding Beijing's efforts.

Vaccine diplomacy is a byproduct of individual nationstates' gravitation toward reactive soft power strategies amid growing nationalism. Vaccine deployment, in a pandemic marked by an immeasurable burden of deaths and a global scope of devastation, is a perfect nation branding space as "a strategic, policy-making approach, designed to help places build on the strengths that will earn them a better reputation" (Anholt 2007, p. 4). Given the currency, novelty, and global scope of COVID-19, for China, vaccine diplomacy as a scientific knowledge-based instrument and IPGs, is a natural choice for nation branding as it leverages on the universality of that suffering and perhaps more than any other public diplomacy instrument, is able to leverage on the emotional appeal that vaccines have for everyone.

Even in Europe, Chinese vaccines have gained traction in parts of the region, despite initial resistance. For a vaccine to be administered, it has to first secure European Medicines Agency (EMA) approval. Although none of China's vaccine manufacturers applied for EMA approval, some Central and Eastern European countries have asked for and 
received enough Chinese vaccines to begin vaccinating their general populations. Serbia used the Sinopharm vaccine whereas Ukraine, Belarus, Herzegovina, Montenegro, Bosnia, and North Macedonia secured Chinese vaccines as well (Table 1). Among EU member states, in February 2021, Hungary was the first EU country to begin COVID-19 vaccinations using China's Sinopharm doses. In March, 2021, the Czech Republic asked China for deliveries of Sinopharm.

In a media-connected world, the boundaries between internal publics and external publics are also increasingly blurred, when nation-states' COVID-19 efforts-good or lacking - are laid bare before global audiences and actors, enabling a greater space for differentiation and comparison, and for uncomfortable questioning including, "Why is my country not doing as well as another country?" or "Why is my country so slow in getting vaccines compared to other countries?" Even without formal rankings and indexes, the Competitive Identity (Anholt 2008) of nation states in COVID-19 manifests itself in the eyes and minds of foreign publics.

In China's case, the soft power dividends from vaccine diplomacy are compelling enough for a country whose nation brand continues to be dogged by unfavorable "madein-China" and "China Threat" undertones. The results of this study show that international sentiments, despite being mostly favorable, were also mixed toward China, as a legacy of its tarnished reputation related to how the pandemic escalated in Wuhan with officials withholding information from the public, underreporting cases, downplaying the severity, and dismissing the likelihood of person-to-person transmission (Wang 2021).

As an authoritarian government, Beijing has centralized public diplomacy instruments in place to design and implement strategic messages and actions successfully around its vaccine diplomacy, but its messages and actions also lack legitimacy and credibility in the eyes of some of Beijing's target publics. Chinese vaccines, with their rapid development, have courted controversy. Chinese authorities allegedly detained vaccine safety advocates, censored information critical of the Chinese-made vaccines, and spread disinformation about non-Chinese vaccines, including a state-led media campaign questioning the efficacy and safety of Western vaccines (Wang 2021). More damaging is the confusion about the efficacy of Chinese vaccines, with mixed results from different trials (Mallapaty 2021). Given that factual basis (Kahraman 2017) or substance (Lee and Kim 2020) are fundamental to nation branding, the safety and efficacy of Chinese vaccines likely impacted Beijing soft power outcomes. In a December 2020 YouGov poll of 19,000 people in 17 countries on perceptions of vaccines, China's vaccines received the second-lowest score, tied with India's. In the Philippines, which ordered 25 million Sinovac doses, less than $20 \%$ of those surveyed expressed confidence in China's vaccines (Wu and Gelineau 2021b). In Singapore, the first shipment of 200,000 Sinovac doses arrived in February 2021, but sat unused for months. Asking Sinovac for more data, Singapore started vaccinating its population with Pfizer and Moderna doses (Dou and Mahtani 2021).

China's nation brand was tarnished by association with the origins of COVID-19 (named "Wuhan virus" initially), but it was also one of few governments that applied a forceful COVID-19 containment approach with significant success. The speed at which its scientists produced vaccinesand in making them available as IPGs to countries left behind by vaccine inequity-also contributed to positive perceptions. It is precisely in such an equivocal space of mixed sentiments that a nation-state would be motivated to shift the negatives and expand the positives to develop a new image to replace an unfavorable one.

Vaccines could serve humanity more if significant collaborations and efforts by global entities are conducted multilaterally. However, Beijing's vaccine diplomacy—nation branding and business opportunities notwithstanding and as an antithesis of vaccine nationalism - are good for improving vaccine access for all. Due to the competition for influence around vaccines among rich nations, poorer countries could gain earlier access to vaccines - assuming that all vaccines are safe and distributed equitably. In this sense, China's contributions of COVID-19 vaccines as IPGs to the world are indeed invaluable.

Beijing is not likely to let up on its efforts to project influence through its national vaccines. The soft power advantage, institutional, and social ecological factors that motivate China's vaccine diplomacy are hard to resist. Although Beijing announced plans to provide Chinese-made vaccines to COVAX, as three Chinese vaccine producers applied to join the initiative for approval of their doses (China to provide 10 million 2021), they do not preclude China from continuing to exercise soft power through its vaccines outside the COVAX framework. The vaccine diplomacy race is far from over as Beijing faces stiffening competition from Russia and India, and now the U.S, who is facing increasing pressure to react to China's vaccine diplomacy outside the COVAX framework.

\section{Declarations}

Conflict of interest The author states that there is no conflict of interest. 


\section{References}

Anholt, S. 2007. Competitive identity: The new brand management for nations, cities, regions. New York: Palgrave Macmillan.

Anholt, S. 2008. From nation branding to competitive identity-the role of brand management as a component of national policy. In Nation branding: Concepts, issues, practice, ed. K. Dinnie, 22-23. Oxford: Elsevier Butterworth-Heinemann.

Beaubien, J. 2021. Price check: Nations pay wildly different prices for vaccine. NPR News, February 19. https://www.npr.org/secti ons/goatsandsoda/2021/02/19/969529969/price-check-nationspay-wildly-different-prices-for-vaccines.

Benabdallah, L. 2021, March 5. Don't believe the hype about China's 'vaccine diplomacy' in Africa. Washington Post. https://www. washingtonpost.com/politics/2021/03/05/dont-believe-hypeabout-chinas-vaccine-diplomacy-africa/.

Bier, L.M., and P.C. Arceneaux. 2020, April 23. Vietnam's “underdog" public diplomacy in the era of COVID-19 pandemic. USC Center on Public Diplomacy. https://www.uscpublicdiplomacy. org/blog/vietnam\%E2\% 80\%99s-\%E2\%80\%9Cunderdog\%E2\% 80\%9D-public-diplomacy-era-covid-19-pandemic.

Biswas, A., and K. Hartley. 2017, November 9. China's soft power struggles. Asia \& the Pacific Policy Society Policy Forum. https://www.policyforum.net/chinas-soft-power-struggles/.

Blablová, V. 2021, March 17. Overview of China's vaccine diplomacy. The Diplomat. https://thediplomat.com/2021/03/thelogic-of-chinas-vaccine-diplomacy/.

Bourne, P.A. 1978. Partnership for international health care. Public Health Reports 93 (2): 114-123.

Bryne, J. 2021, January 11. Indonesia green lights China's Sinovac COVID-19 vaccine. Biopharma Reporter. https://www.bioph arma-reporter.com/Article/2021/01/11/Indonesia-green-lightsChina-s-Sinovac-COVID-19-vaccine.

Cao, W. 2016. Is China's public diplomacy effective? The Chinese Journal of International Politics 9 (4): 399-434.

China to provide 10 million vaccine doses to COVAX initiative. 2021, February 3. Reuters. https://www.reuters.com/article/ushealth-coronavirus-vaccine-china/china-to-provide-10-millionvaccine-doses-to-covax-initiative-idUSKBN2A30VZ.

Chinese State Council Information Office. 2014. Chinese state council information office brief on the Ebola epidemic prevention and control assistance. https://coek.info/pdf-chinas-publicdiplomatic-networks-on-the-ebola-issue-in-west-africa-issuesmanag.html.

Chitty, N. 2017. Soft power, civic virtue and world politics (section overview). In The Routledge handbook of soft power, ed. N. Chitty, L. Ji, G.D. Rawnsley, and C. Hayden, 9-36. London: Routledge/Taylor and Francis.

Cohen, J. 2020. With global push for COVID-19 vaccines, China aims to win friends and cut deals. Science. https://doi.org/10.1126/scien ce.abf8838.

Cooper, R. 2003. The breaking of nations. Order and chaos in the 21st century. Boston: Atlantic Monthly Press.

D'Hooghe, I. 2011. The expansion of China's public diplomacy system. In Soft power in China, ed. J. Wang, 19-35. Basingstoke: Palgrave Macmillan.

Doherty, B., D. Hurst, and K. Lyons, 2021. Coercion or altruism: Is China using its Covid vaccines to wield global power? The Guardian, March 27. https://www.theguardian.com/australia-news/ 2021/mar/28/coercion-or-altruism-is-china-using-its-covid-vacci nes-to-wield-global-power.

Dou, E., and S. Mahtani. 2021. China's vaccine diplomacy stumbles as clinical trial data remains absent. Washington Post, March 22. https://www.washingtonpost.com/world/asia_pacific/china-coron avirus-singapore-data/2021/03/23/7a0582ca-8afc-11eb-a33eda28941cb9ac_story.html.

Ellwood. 2021. Vaccine diplomacy: A new chapter in the story of soft power, March 17. https://uscpublicdiplomacy.org/blog/vaccinediplomacy-new-chapter-story-soft-power.

Fan, Y. 2006. Banding the nation: What is being branded? Journal of Vacation Marketing 12 (1): 5-14.

Fan, Y. 2010. Branding the nation: Towards a better understanding. Place Branding and Public Diplomacy 6 (2): 97-103.

Fauci, A.S. 2007. The expanding global health agenda: A welcome development. Nature Medicine 13: 1169-1171. https://doi.org/ 10.1038/nm1646.

Germany retains top "Nation Brand" ranking, US and China experience significant decline. 2021. IPSOS. https://www.ipsos.com/en-us/ news-polls/Germany-Retains-Top-Nation-Brand-Ranking-theUnited-Kingdom-emerges-ahead-of-Canada-to-Round-Out-theTop-Three-US-and-China-Experience-Significant-Decline.

Global Soft Power Index. 2020. China in Top 10. https://brandfinance. $\mathrm{com} /$ press-releases/global-soft-power-index-china-in-top-10-butstunted-by-covid-19.

Gomez, E.J. 2014. Cuba's health diplomacy in the age of Ebola. $B B C$, November 14. https://www.bbc.com/news/world-latin-america29984688.

Groll, E. 2013. Cuba's great export? Medical diplomacy. Foreign Policy, May 7. https://foreignpolicy.com/2013/05/07/cubas-great est-export-medical-diplomacy/.

Harling, K. 2012. An overview of case study. SSRN. https://doi.org/ $10.2139 /$ ssrn. 2141476

Hotez, P.J. 2001. Vaccines as instruments of foreign policy. Embo Reports. https://doi.org/10.1093/embo-reports/kve215.

Hotez, P.J. 2010. Peace through vaccine diplomacy. Science 327 (5971): 1301.

Hotez, P.J. 2014. Vaccine diplomacy: Historical perspectives and future direction. PLOS Neglected Tropical Diseases 8 (6): e2808.

$\mathrm{Hu}$, Y. 2020. China's vaccines better suit Africa, LatAm due to 'lower costs, easier logistics.' Global Times, December 1. https://www. globaltimes.cn/content/1208668.shtml.

Huang, Y. 2021. Vaccine diplomacy is paying off for China. Foreign Affairs, March 11. https://www.foreignaffairs.com/articles/china/ 2021-03-11/vaccine-diplomacy-paying-china.

$\mathrm{Xi}$ Jinping makes an important speech at working conference for neighborhood diplomacy. 2013. People's Daily, October 25. http://polit ics.people.com.cn/n/2013/1025/c1024-23332318.html.

Kahraman, A. 2017. A methodological approach to nation branding. In The Routledge handbook of soft power, ed. N. Chitty, L. Ji, G.D. Rawnsley, and C. Hayden, 93-103. London: Routledge, Taylor and Francis.

Karásková, I., and V. Blablová. 2021. The logic of China's vaccine diplomacy. The Diplomat, March 24. https://thediplomat.com/ 2021/03/the-logic-of-chinas-vaccine-diplomacy/.

Katz, R., S. Kornblet, G. Arnold, E. Lief, and J.E. Fischer. 2011. Defining health diplomacy: Changing demands in the era of globalization. Milbank Quarterly 89: 503-523.

Kelman, I. 2019. Do health interventions support peace through "disaster diplomacy?" Peace Review 31 (2): 158-167.

Kickbusch, I., G. Silberschmidt, and P. Buss. 2007. Global health diplomacy: The need for new perspectives, strategic approaches and skills in global health. Bulletin of the World Health Organization 85: 230-232.

Krasnyak, O. 2018. National styles in science diplomacy: China. USC Center on Public Diplomacy, December 13. https://uscpublicd iplomacy.org/blog/national-styles-science-diplomacy-china.

Lancaster, K., and M. Rubin. 2020. Assessing the early response to Beijing's pandemic diplomacy. Council on Foreign Relations, April 30. https://www.cfr.org/blog/assessing-early-response-beiji ngs-pandemic-diplomacy. 
Lawler, D. 2021. Biden's next challenge: Vaccine diplomacy. Axios, March 22. https://www.axios.com/us-coronavirus-vaccine-diplo macy-china-exports-4a5c7bbd-32fb-468a-add5-9b1689bf5ce3. html.

Lee, S.T., and H.S. Kim. 2020. Nation branding in the COVID-19 era: South Korea's pandemic public diplomacy. Place Branding and Public Diplomacy. https://doi.org/10.1057/s41254-020-00189-w.

Li, H.Y., and S. Wong. 2018. The evolution of Chinese public diplomacy and the rise of think tanks. Place Branding and Public Diplomacy 14 (1): 36-46.

Liu, A. 2020. Sinopharm chief says COVID-19 vaccine will cost less than $\$ 145$ for 2-dose regimen. Fierce Pharma, August 18. https:// www.fiercepharma.com/vaccines/china-sinopharm-chief-narrowsdown-covid-19-vaccine-price-to-within-145-for-2-dose-regimen.

Mallapaty, S. 2021. China COVID vaccine reports mixed results-what does that mean for the pandemic? Nature. https://doi.org/10.1038/ d41586-021-00094-z.

McGregor, G. 2020. How China's COVID-19 vaccines could fill the gaps left by Pfizer, Moderna, AstraZeneca. Fortune, December 5. https://fortune.com/2020/12/05/china-covid-19-vaccines-appro val-sinovac-sinopharm/.

Ministry of Foreign Affairs of the People's Republic of China. 2020. Foreign Ministry spokesperson Hua Chunying's remarks on China joining COVAX, October 9. https://www.fmprc.gov.cn/mfa_eng/ xwfw_665399/s2510_665401/2535_665405/t1822631.shtml.

Mullen, T. 2017. Introduction to sentiment analysis. https://lctmaster. org/files/MullenSentimentCourseSlides.pdf.

Ndebele, L. 2021. Thanks China, your vaccines are a 'light at the end of a dark tunnel': Zim. Sunday Times Daily, February 15. https://www. timeslive.co.za/sundaytimes-daily/africa/2021-02-15-thanks-china-your-vacci nes-are-a-light-at-the-end-of-a-dark-tunnel-zim/.

Nugent, C., and C. Campbell. 2021. The U.S. and China are battling for influence in Latin America, and the pandemic has raised the stakes. Time, February 4. https://time.com/5936037/us-chinalatin-america-influence/.

Nye, J. 2008. Public diplomacy and soft power. Annals of the American Academy of Political and Social Science 616 (1): 94-109.

Nye, J. 2015. The limits of Chinese soft power. Belfer Center for Science and International Affairs, Harvard University. https://www. belfercenter.org/publication/limits-chinese-soft-power

COVID-19 data explorer. 2021. Oxford University: Our world in data. https://ourworldindata.org/covid-vaccinations.

Preston, F., B. Bailey, S. Bradley, J. Wei, and C. Zhao. 2016. Navigating the new normal: China and global resource management. Development Research Center of the State Council and Chatham House Report. https://www.chathamhouse.org/2016/01/navig ating-new-normal-china-and-global-resource-governance.

Ruffini, P. 2017. Science and diplomacy. A new dimension of international relations. Berlin: Springer.

Safi, M. 2021. Vaccine diplomacy: West falling behind in race for influence. The Guardian, February 19. https://www.theguardian.com/ world/2021/feb/19/coronavirus-vaccine-diplomacy-west-fallingbehind-russia-china-race-influence.

Shakeel, S.I., M. Brown, S. Sethi, and H. Mackey. 2019. Achieving the end game: Employing "vaccine diplomacy" to eradicate polio in Pakistan. BMC Public Health 19: 79-88.

Silver, L., K. Devlin, and C. Huang. 2020. Unfavorable views of China reach historic highs in many countries. Pew Center, October 6. https://www.pewresearch.org/global/2020/10/06/unfavorableviews-of-china-reach-historic-highs-in-many-countries/.

UN launches 'Only Together' campaign to support global vaccine equity call. 2021, March 11. https://news.un.org/en/story/2021/ 03/1087072.

Wang, Y. 2021. China's Dangerous games around vaccines. Humans Rights Watch, March 4. https://www.hrw.org/news/2021/03/04/ chinas-dangerous-game-around-covid-19-vaccines.

Ward, V., R. West, S. Smith, S. McDermott, J. Keen, R. Pawson, and A. House. 2014. The role of informal networks in creating knowledge among health-care managers: A prospective case study. Health Services and Delivery Research. https://doi.org/10.3310/hsdr0 2120.

Watson, K. 2021. U.S. looking to loan AstraZeneca COVID-19 vaccine doses to Canada and Mexico. CBS, May 18. https://www.cbsne ws.com/news/astrazeneca-covid-19-vaccine-loan-mexico-canada/.

Wheaton, S. 2020. Chinese vaccine would be 'global public good,'Xi says. Arlington: Politico.

Wu, H., and K. Gelineau. 2021a. Chinese vaccines sweep much of the world, despite concerns. New York: Associated Press.

Wu, H. and K. Gelineau. 2021b. China ships millions of COVID-19 vaccines to poor nations abroad; denies 'vaccine diplomacy.' CP 24, March 2. https://www.cp24.com/world/china-ships-milli ons-of-covid-19-vaccines-to-poor-nations-abroad-denies-vacci ne-diplomacy-1.5329782.

Xi, J. July 18, 2014. Carry forward traditional friendship and jointly open up new chapter of cooperation [Hongyang chuantong youhua, gongpu hezuo xin pian]. People's Daily, p. 1.

Yang, Y. 2020. Looking inward: How does Chinese public diplomacy work at home? The British Journal of Politics and International Relations 22 (3): 369-386.

Yin, R. 1984. Case study research: Design and methods, 1st ed. Thousand Oaks: Sage.

Yin, R. 2014. Case study research: Design and methods, 5th ed. Thousand Oaks: Sage.

Zhao, K. 2017. China's public diplomacy for international public goods. Politics \& Policy 45 (5): 706-732.

Zhao, K. 2019. The China model of public diplomacy and its future. In Debating public diplomacy, pp. 169-181. Leiden: Brill Nijhoff.

Publisher's Note Springer Nature remains neutral with regard to jurisdictional claims in published maps and institutional affiliations.

Seow Ting Lee is professor of strategic communication in the Department of Advertising, Public Relations and Media Design at the University of Colorado in Boulder. Her research in strategic communication focuses on public relations and health communication. She studies organization-stakeholder communication strategies and practices, with an emphasis on new media. Her research has been published in leading, peer-reviewed journals including Journal of Communication, Public Relations Review, Journal of Public Relations Research, Journal of Health Communication, Health Communication, Media Culture and Society, Mass Communication and Society, Health Promotion International, Journal of Mass Media Ethics, and Place Branding and Public Diplomacy. 